\title{
Environmental Experience Modulates Ischemia-Induced Amyloidogenesis and Enhances Functional Recovery
}

\author{
Teresita L. Briones, Magdalena Rogozinska, and Julie Woods
}

\begin{abstract}
In this study, we examined whether ischemia-induced amyloidogenesis could be modulated by environmental "experience," and whether this modulation is associated with improved cognitive functioning. Rats were subjected to either global ischemia or sham surgery and then were randomly assigned to either enriched environment housing (EE) or socially paired housing (controls). After 14 days of differential environmental housing, the rats were tested in the water maze. Our results show decreased C-terminal fragments of the $\beta$-amyloid precursor protein $(\beta \mathrm{APP})$ and decreased amyloid beta $(\mathrm{A} \beta)$ load in the ischemic EE rats compared to the ischemic control animals. In addition, $\mathrm{A} \beta$ oligomerization was significantly decreased in the ischemic EE animals compared to the ischemic control rats. Further, significantly increased levels of neprilysin, but not insulindegrading enzyme, amyloid-degrading enzymes, were seen in the ischemic EE rats compared to the ischemic control animals. Behavioral analyses showed that ischemic EE rats performed significantly better on the memory task compared to the ischemic control group. These results suggest that use of multi-sensory environmental enrichment following cerebral ischemia may reduce the accumulation of $\mathrm{A} \beta$ peptide in the more pathologic oligomeric form, and consequently may enhance functional recovery.
\end{abstract}

Key words: $\mathrm{A} \beta$ oligomers; $\beta$-secretase amyloid cleaving enzyme (BACE); enriched environment; learning and memory; water maze

\section{Introduction}

$C_{\mathrm{axp}}$ EREBRAL ISCHEMIC INJURY RESULTS IN INCREASED intraaxonal $\beta$-amyloid precursor protein ( $\beta \mathrm{APP})$ levels and promotes the accumulation of the $\mathrm{A} \beta$ peptide in the human brain (Kalaria et al., 1993a; Smith et al., 2003). In rodents, the $\beta$ APP level also increases in the brain after cerebral ischemia (Banati et al., 1995; Kalaria et al., 1993b; Pluta, 2002; PopaWagner et al., 1998), and evidence of increased A $\beta$ deposition is present as well (Ishimaru et al., 1996; Nihashi et al., 2001; Popa-Wagner et al., 1998). Increased $\beta$ APP expression is localized in axonal swellings, dystrophic neurites, and neuronal perikarya along the periphery of the infarct at 4 and 7 days after ischemic injury (Kalaria et al., 1993a). Meanwhile, accumulation of $\mathrm{A} \beta$ in ischemic injury is seen mainly in the infarct core approximately 1 week after ischemia (Popa-Wagner et al., 1998).

Evidence for the role of $\beta \mathrm{APP}$ in physiologic functioning suggests its involvement in the regulation of neuronal growth and survival (Mattson, 1997; Selkoe et al., 1997). However, its role in central nervous system (CNS) pathology is still not completely understood. Normal processing usually leads to the cleavage of $\beta \mathrm{APP}$ in the middle of the $\beta$-amyloidogenic sequence, resulting in the generation of the secreted form of BAPP (Popa-Wagner et al., 1998; Selkoe et al., 1997). On the other hand, the presence of CNS pathology is believed to lead to alternative processing initiated by the $\beta$-secretase amyloid cleaving enzyme (BACE), resulting in the production of the carboxyl-terminal portion of $\beta \mathrm{APP}$, and the liberation and accumulation of $\mathrm{A} \beta$ oligomers, which can be neurotoxic (Cleary et al., 2005; Klyubin et al., 2005; Popa-Wagner et al., 1998; Wen et al., 2004). Furthermore, the carboxyl-terminal fragment of $\beta \mathrm{APP}$ is shown to destabilize calcium homeostasis and renders neuronal cells vulnerable to glutamateinduced excitotoxicity (Kim et al., 1998).

One strategy that may moderate the increased $\mathrm{A} \beta$ production and oligomerization seen in cerebral ischemia is enriched environment (EE) housing. EE housing is a behavioral paradigm that involves the use of multi-sensory stimulation. Compelling evidence exists demonstrating the effects of EE housing on increased neuronal activity, leading to changes in dendritic branching, spine density, and the number

University of Illinois at Chicago, Chicago, Illinois. 
of synapses in the visual and motor cortices (Briones et al., 2004a; Greenough and Volkmar, 1973; van Praag et al., 2000; West and Greenough, 1972), as well as turnover of neurotransmitters such as acetylcholine (Escorihuela et al., 1995; Jones and Schallert, 1992). In traumatic head injury, EE housing has beneficial effects not only in aiding functional recovery (Hicks et al., 2002), but also in decreasing lesion size (Passineau et al., 2001), promoting the survival of progenitor cells (Gaulke et al., 2005), and increasing brain-derived neurotrophic factor (Chen et al., 2005) and dopamine levels (Wagner et al., 2005). Because of the combined evidence that shows the effects of EE housing in increasing neuronal activity, and that neuronal activity can affect the processing of $\beta$ APP (Kamenetz et al., 2003), we examined if ischemia-induced increase in $\mathrm{A} \beta$ burden can be modulated by "experience" in an enriched environment. We also examined whether the modulation of $\mathrm{A} \beta$ load by environmental experience is associated with the amelioration of ischemia-induced cognitive impairment.

\section{Methods}

\section{Cerebral ischemia}

The four-vessel occlusion method was used to induce transient global cerebral ischemia as described previously (Briones et al., 2004b). Adult male Wistar rats 3-4 months of age (body weight 350-375 $\mathrm{g}$ at the time of surgery) were used in the study. Briefly, rats were anesthetized with an isofluorane/oxygen ( $2.5 \%$ isofluorane and $30 \%$ oxygen) mixture on the first day and an incision was made to isolate both common carotid arteries. Immediately following isolation of both carotid arteries, the vertebral arteries were electrocauterized in the alar foramina at the level of the first cervical vertebra. Body temperature was maintained at $37-37.5^{\circ} \mathrm{C}$ with a heating pad during the surgical procedure and until the animals were fully recovered. The next day, both common carotid arteries were occluded for $12 \mathrm{~min}$ while the animals were awake. This period of carotid occlusion was used because it results in damage confined to the hippocampal area (Briones et al., 2005; Briones et al., 2000). The criterion used to determine transient global cerebral ischemia was the bilateral loss of the righting reflex within 2 min of occlusion. Animals that developed postoperative complications such as excessive weight loss ( $>20 \%$ of preoperative body weight, $n=2)$ were excluded from the study. In addition, pain level was assessed by observing for sluggishness, extreme aversion to being touched, and weight loss. The animals were not given any postoperative analgesia but were euthanized immediately when persistent pain was observed $(n=1)$. A total of 48 animals were included in the study. Sham-operated animals were subjected to the same anesthesia and surgery that consisted of a neck incision without carotid manipulation and an incision behind the occipital bone without cauterization of the vertebral arteries. All efforts were made to minimize animal distress and to reduce the number of animals used. Experimental protocols in this study were approved by the Institutional Animal Care and Use Committee and were in accordance with the National Institutes of Health guidelines.

\section{Animal housing}

After 3 days of recovery, the rats were randomly assigned to either EE housing or paired housing (controls). The rats remained in their assigned housing condition for 14 days. All animals were housed in the same room under a 12-h light:12-h dark cycle and had free access to food and water. Room temperature was maintained at $22 \pm 2{ }^{\circ} \mathrm{C}$ and the noise level was kept to a minimum. Animals in the EE group ( $n=12$ ischemic and $n=12$ shams) were housed together in a sensory-rich living condition (a wire cage measuring $2 \times 1 \times 1.65 \mathrm{~m}$ ) consisting of a variety of objects such as toys, wooden blocks, running wheels, acrylic glass tunnels, ladders, plastic castles, and swings, as described previously (Briones et al., 2004b). Approximately 8 rats $(n=4$ ischemic and $n=4$ shams) were kept in EE at one time. In addition, these rats were placed each day in an open field $(1.2 \times 1.2 \times 1.2 \mathrm{~m})$ with a novel arrangement of toys and objects and allowed to explore for $30 \mathrm{~min}$ while the objects in the home cage were being changed. Objects in both EE housing and the open field were changed daily to maintain novelty.

Animals assigned to the control (CON) group ( $n=12$ ischemic and $n=12$ shams) were housed in pairs in standard laboratory cages $(16.5 \times 22.5 \times 13.5 \mathrm{~cm})$. Although rats in this group were able to observe the ongoing activity of the room, they did not receive any stimulation and contact was limited to daily handling and routine cage changing.

\section{Behavioral testing}

Spatial learning and memory were examined in the water maze after 14 days of differential housing as described previously (Briones et al., 2006a). During testing, the tub was filled with tepid water $\left(22 \pm 2{ }^{\circ} \mathrm{C}\right)$ and made opaque by the addition of powdered milk. An inverted white flowerpot submerged $2 \mathrm{~cm}$ beneath the water surface served as the goal and the opaqueness of the water enabled the goal to be concealed. The pool was divided into 4 quadrants of equal surface area and the starting locations for testing were assigned north, south, east, and west. The goal was located in the middle of the northeast quadrant approximately $22 \mathrm{~cm}$ from the pool rim. The day before actual testing started, the rats were allowed a habituation swim for $10 \mathrm{sec}$ without the goal. The constant water temperature and habituation swim were used to decrease animal stress associated with water maze testing. The animals received four trials a day for 4 consecutive days. The day after the spatial learning test, a probe trial of $60 \mathrm{sec}$ without the goal was done to assess how well the rats remembered the location of the goal. The traditional measures of swim latency (time to reach the platform) and the path taken by the animals to locate the goal were recorded for the spatial learning and memory task. Furthermore, swimming speed (path length/swim latency) was recorded to assess the motor activity of the rats in performing the task. In the probe trial, the time spent on the previous goal location (correct target quadrant) was recorded. Search errors in the probe trial, which represent the number of entries made to incorrect quadrants in the pool, were recorded as well. An error was designated only if the rat's entire body (excluding the tail) was in an incorrect quadrant. All recordings were done by a video camera connected to an image analyzer (Water Maze Version 4.20 , Columbus, $\mathrm{OH}$ ). The animals were allowed to swim for a maximum of $180 \mathrm{sec}$ per trial. This maximum limit was chosen to prevent fatigue. If an animal did not locate the platform within this time, the experimenter guided the rat to the platform, and it was given a swim latency score of $180 \mathrm{sec}$. Once 
the animals were on the platform, they were allowed to remain there for $20 \mathrm{sec}$ to allow orientation to visual cues in the room.

Given that neurodegeneration in the retina and optic nerve (Davidson et al., 2000), as well as motor deficits (Bouët et al., 2007; Yi et al., 2007) can occur in cerebral ischemia, four cuedplatform trials were given before behavioral testing to rule out impairments in vision and mobility. For these trials, the platform was placed in a quadrant different from that used during the behavioral testing and the goal was marked with a visible black cube.

\section{Tissue preparation}

The day after the completion of behavioral testing, all the rats were euthanized using $\mathrm{CO}_{2}$ inhalation, and the brains were removed, cut in half sagittally, and immediately placed in liquid nitrogen until processing. Half of the brain was used for Fluoro-Jade staining and immunohistochemistry while the other half was used for Western blot analysis. For all analyses, the entire hippocampus was examined.

\section{Immunohistochemistry}

Fixed brains (fixative was $4 \%$ paraformaldehyde in $0.1 \mathrm{M}$ phosphate buffer, $\mathrm{pH}$ 7.3) were sectioned at 30- $\mu \mathrm{m}$ thickness using a cryostat. Tissue sections were obtained covering the entire hippocampal region in its rostro-caudal extension, and the free-floating sections were first treated with $0.3 \%$ hydrogen peroxide in PBS to inactivate endogenous peroxidase activity. After inactivation, the tissues were rinsed and placed in the blocking solution of $3 \%$ serum, $0.1 \%$ Triton- $X$, and $1 \%$ bovine serum albumin for $1 \mathrm{~h}$, then washed in $0.1 \mathrm{M}$ PBS $(\mathrm{pH} 7.3)$ followed by incubation for $48 \mathrm{~h}$ at $4^{\circ} \mathrm{C}$ with antibody recognizing either the: (1) $N$-terminal epitope of $\beta$ APP (mab22C11, 1:500; Chemicon, Temecula, CA), (2) cytoplasmic carboxyl fragment 643-695 of $\beta$ APP (clone 2.F2.19B4, 1:200; Chemicon), or (3) extracellular A $\beta$ (mab4G8, 1:500; Signet Laboratories, Dedham, MA). The primary antibodies were detected using biotinylated IgG secondary antibodies (1:200; Vector Laboratories, Burlingame, CA) for $1 \mathrm{~h}$ at room temperature. The tissues were then washed and incubated in avidin-biotin complex (ABC kit; Vector Laboratories) for $1 \mathrm{~h}$ at room temperature. Immunoreactions were visualized by treatment of tissue sections with hydrogen peroxide and 3,3'-diaminobenzidine tetrahydrochloride in Tris buffer ( $\mathrm{pH}$ 7.3) enhanced with nickel. After thorough rinsing, the tissue sections were mounted on gelatin-coated slides, dried, and cover-slipped. Tissues from all experimental groups were run simultaneously and under identical conditions to ensure reproducibility of results. In all immunohistochemical experiments, pre-dilution tests were done to ensure specificity of the antibodies and negative controls, involving deletion of the primary antibodies, and these were used to rule out any nonspecific interactions.

The stereological method of surface density (Sv) measurement was used to quantify $\beta$ APP immunoreactivity, wherein a set of test lines (cycloid arcs) was superimposed on light microscopic images and the intersections between the test lines and immunoreactive cells were counted. The surface density was then calculated using the formula: $\mathrm{Sv}=2(\mathrm{I} / \mathrm{L})$, where I is the total number of intersections summed over all samples (6 samples/animal were used), and L is the total length of the test line within the sample area $(528 \mu \mathrm{m})$.
Amyloid load was determined by the quantification of the surface area covered by $\mathrm{A} \beta$ immunoreactivity using an areafractionator grid defined by the StereoInvestigator (MicroBrightfield, Colchester, VT) computerized analysis system. This technique provided a methodical system for estimating the area occupied by $\mathrm{A} \beta$ by counting a regularly spaced fraction of the total hippocampal region. The counting frame was set to $80 \times 120 \mu \mathrm{m}$, the scan grid $340 \times 340 \mu \mathrm{m}$, and the Cavalieri grid spacing to $30 \mu \mathrm{m}$ at $40 \times$ magnification. The percentage of coverage in four sections was averaged to obtain a final estimate of amyloid burden for each animal.

\section{Western blot}

Since the currently available commercial antibodies do not allow accurate quantitation of processed $\beta$ APP fragments by immunohistochemistry, Western blots were also used to detect mab22C11 antibody band size (1:1000); also, levels of BACE1 (1:50; Calbiochem, San Diego, CA) were detected and results were compared to NT- and CT-fragment expressions from immunostaining, respectively. Levels of $\mathrm{A} \beta$-degrading enzymes were also examined using Western blot analysis. Dissected hippocampal tissues were homogenized in extraction buffer ( $50 \mathrm{mM}$ Tris, $\mathrm{pH} 7.2), 150 \mathrm{mM} \mathrm{NaCl}, 5 \mathrm{mM}$ EDTA, protease inhibitor mixture (Sigma, St. Louis, MO), and $100 \mathrm{mM}$ phenylmethylsulfonyl fluoride (Sigma) using glass microhomogenizers. Following addition of $1 \%$ SDS, the homogenates were centrifuged at $25,000 \times \mathrm{g}$ for $20 \mathrm{~min}$. Aliqouts from the supernatant were removed for protein determination. The remaining supernatant was collected, mixed with solubilizer containing SDS, glycerine, EDTA, Tris, bromphenol blue, and dithiothreitol, boiled for $5 \mathrm{~min}$ at $95^{\circ} \mathrm{C}$, and stored at $-20^{\circ} \mathrm{C}$ until ready for use. Protein concentration in samples was determined using the BCA-Protein assay (Pierce, Rockford, IL). The primary antibodies used to determine levels of amyloid-degrading enzymes were anti-neprilysin (1:50; Novocastra Laboratories, Newcastle upon Tyne, U.K.) and anti-insulin-degrading enzyme (1:1000; Chemicon International, Temecula, CA).

Formation of $\mathrm{A} \beta$ oligomers was also examined by Western blot. After tissue homogenization as described above, some of the samples were removed for extraction of soluble amyloid peptide. Samples were centrifuged at $78,500 \times \mathrm{g}$ for $1 \mathrm{~h}$ at $4^{\circ}$ and the supernatant was removed and processed as described above. The antibodies used were anti-6E10 (1:500; Signet Laboratories, Dedham, MA) to determine levels of $\mathrm{A} \beta$ monomers, and anti-A11 (1:200; Biosource, Carlsbad, CA) to determine levels of $\mathrm{A} \beta$ oligomers.

For Western blot analyses, equal amounts of protein $(40 \mu \mathrm{g})$ from each rat were loaded and separated by SDS-PAGE in $8-16 \%$ acrylamide gradient gels. The protein bands then were electrophoretically transferred to nitrocellulose membranes (Amersham, Piscataway, NJ) using Towbin's buffer with $0.1 \mathrm{~g} / \mathrm{L}$ SDS and $100 \mathrm{~mL} / \mathrm{L}$ methanol added. After transfer, the membranes were stained with $0.5 \%$ Ponceau Red to visualize total proteins, then de-stained. Non-specific binding sites were blocked by incubation of the membranes for $1 \mathrm{~h}$ at room temperature in 5\% powdered milk in Tris-buffered saline containing $0.5 \mathrm{~mL} / \mathrm{L}$ Tween-20. After blocking, the membranes were incubated overnight at $4^{\circ} \mathrm{C}$ with gentle agitation in the primary antibody. The secondary antibodies used were horseradish peroxidase-conjugated immunoglobulin (Sigma) 

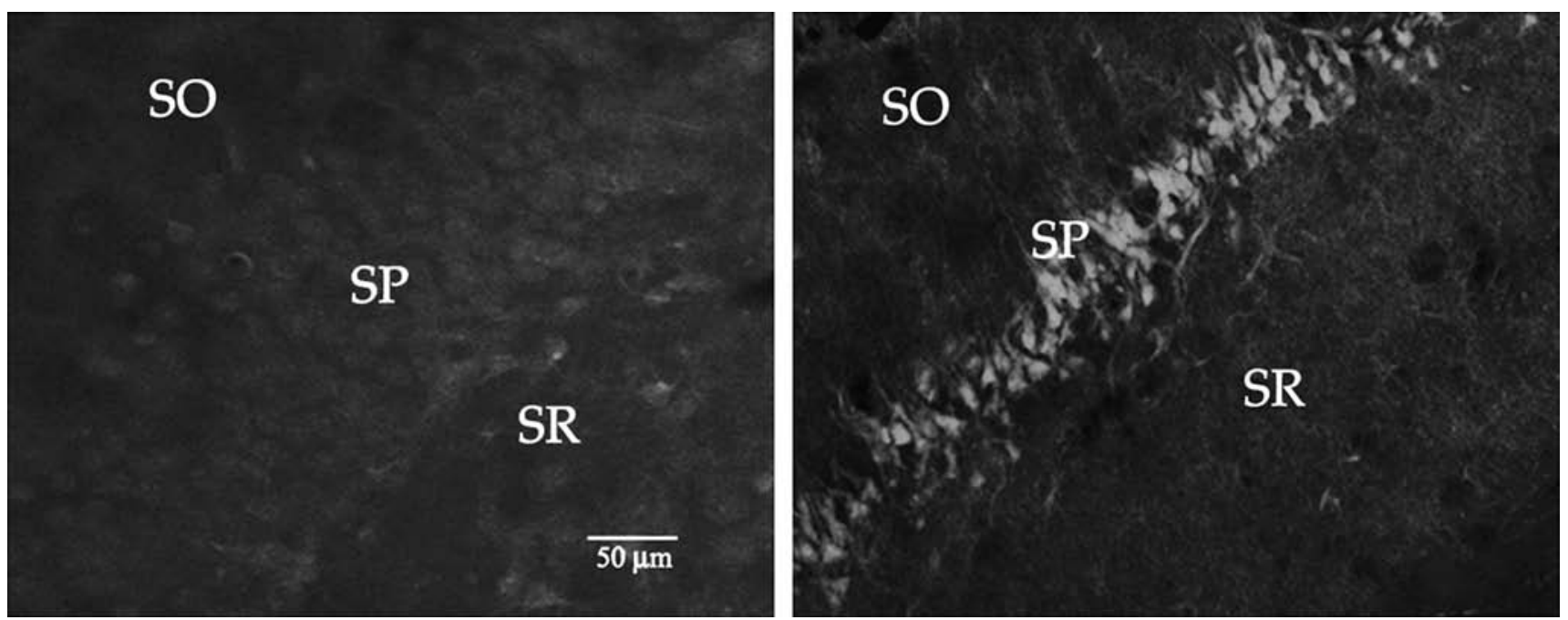

FIG. 1. Representative photomicrographs of Fluoro-Jade-stained hippocampal neurons in the dorsal region. Brightly fluorescent cells are evident in the ischemic rats (right image), which denotes neurodegeneration. Meanwhile no fluorescent staining was seen in the sham-operated rats (left image). The scale bar is for both photomicrographs (SO, stratum oriens layer in the hippocampus; SP, stratum pyramidale; SR, stratum radiatum).

and the Super Signal chemiluminescence substrate kit (Pierce) was used to visualize immunoreactive bands. After visualization, the membranes were stained with Amido black to qualitatively verify protein loading. A series of dilutions were performed and immunoblotted for each antibody to establish that the relationship between protein band and intensity was linear over the range of band intensities observed in the samples. Band visualization was obtained by exposure of membranes to autoradiographic film (Kodak Biomax ${ }^{\mathrm{TM}}$; Eastman Kodak, Rochester, NY). Quantification of differences in protein bands between samples was done using densitometric analysis (Scion Image Beta 4.0.2, Frederick, MD). Reference proteins were not used for normalization because they have been reported to vary under certain experimental conditions (Bhatia et al., 1994; Thellin et al., 1999); instead, samples were analyzed in quadruplicate. Results of quadruplicate measurements were averaged and used as one individual data point for statistical analysis. Densitometric values were calculated as: density of sample band/density of background. The values obtained were then converted to percentage for the sham group, since EE housing did not have any significant effects on CT- $\beta$ APP expression, $\mathrm{A} \beta$ load, $\mathrm{A} \beta$ oligomerization, and levels of amyloid-degrading enzymes in the animals.

\section{Fluoro-jade staining}

To assess the degree of neuronal loss due to ischemia, tissue sections adjacent to the ones used for immunohistochemistry were stained with Fluoro-Jade. Sections were mounted on gelatin-coated slides, dried in a slide warmer, and then rehydrated in distilled water for $1 \mathrm{~min}$, followed by descending grades of alcohol for $3 \mathrm{~min}$. Once rehydrated, the slides were placed in a Coplin jar with $0.06 \%$ potassium permanganate for $15 \mathrm{~min}$ on a rotating platform. Pre-treatment with potassium permanganate was necessary to reduce background staining. After pre-treatment, the slides were rinsed in distilled water for $1 \mathrm{~min}$ and then transferred to the Fluoro-Jade staining solution $(0.001 \%$ Fluoro-Jade in acetic acid) for $30 \mathrm{~min}$, rinsed again in distilled water for 3 changes ( 1 min each), then airdried. Finally, sections were immersed in Histoclear and cover-slipped using DPX mounting medium.

The stained sections were examined under an epifluorescence microscope (Nikon E800, Nikon, Melville, NY) with an FITC fluorescence filter cube, and counting of degenerated neurons was done in the hippocampus proper (regions CA1CA3), but was restricted to the stratum pyramidale layer. The optical fractionator method in the StereoInvestigator computerized analysis system was used for quantitative analysis, and the sampling parameters used were as follows: counting frame area $=6200 \mu \mathrm{m}^{2}$, area of the sampling fraction (ASF) $=$ $0.10 \mu \mathrm{m}^{2}$ (dissector frame area/square of the distance between dissectors), section sampling fraction (SSF) $=0.125$ (6 sections out of 48 total sections), the height of each dissector was $20 \mu \mathrm{m}$, the guard height was $0.5 \mu \mathrm{m}$, and the thickness of the sampling fraction (TSF) $=0.67 \mu \mathrm{m}$ (dissector height/tissue section thickness). The total number of Fluoro-Jade-positive cells was then calculated as: the number of Fluoro-Jadestained cells counted $\left(\Sigma Q^{-}\right)$, multiplied by the inverse fraction of SSF, ASF, and TSF.

\section{Statistical analysis}

The SAS general linear model (SAS Institute, Cary, NC) procedures for two-way analysis of variance (ANOVA) were used to examine effects of injury, differential housing, and injury and differential housing interaction. When appropriate, the SAS CONTRAST statement was used for planned comparisons of the effects of injury (ischemic groups versus sham groups), differential housing (EE versus $\mathrm{CON}$ ), and the combination of injury and rehabilitation training (ischemic and differential housing versus sham and differential housing) on $\beta \mathrm{APP}$ and $\mathrm{A} \beta$ immunoreactivity, and levels of BACE, neprilysin (NEP), insulin-degrading enzyme (IDE), A $\beta$ oligomerization, time spent in the correct quadrant of the pool, and search errors in the probe trial. All slides used for analysis were coded to preclude experimenter bias. Meanwhile the 
behavioral data were analyzed using the SAS general linear model procedures for two-way ANOVA with repeated measures to determine differences in swim latency, path length, and swimming speed.

\section{Results}

\section{Neuron loss}

Ischemia-induced neuronal loss was quantified in the Fluoro-Jade-stained tissues. As expected, ischemia resulted in selective neurodegeneration in the pyramidal neurons at the CA1 sector of the dorsal hippocampus with relative sparing of CA3 neurons, while no staining was evident in the ventral hippocampus (Fig. 1). No Fluoro-Jade-stained cells were seen in the sham-operated animals. The susceptibility of the CA1 region and relative antero-ventral gradient vulnerability of hippocampal neurons to cerebral ischemia as reported by others (Kirino, 2000; Wen et al., 2004), was further confirmed in this study; however, the mechanism(s) responsible for this differential neuronal vulnerability to ischemic injury is still poorly understood.

Further examination of tissue sections revealed that histofluorescent labeling was brighter in the soma, with some staining observed in the dendritic processes. Quantifiable Fluoro-Jade-positive cells were seen mainly in the stratum pyramidale of the CA1 region. No significant differences were seen in the number of Fluoro-Jade-positive cells between ischemic rats in the EE group $(1102 \pm 155)$ and those assigned to

\section{A}

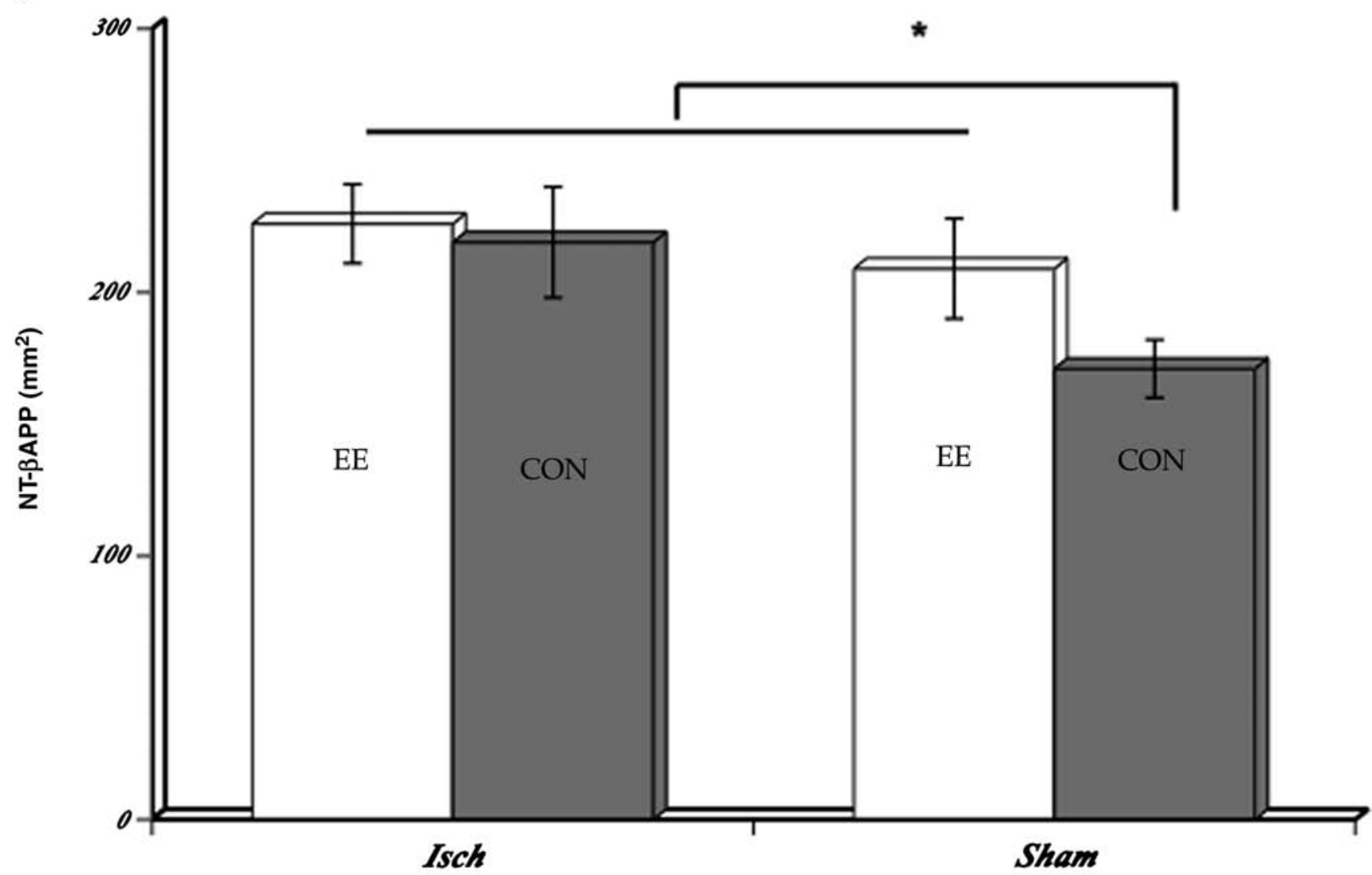

B

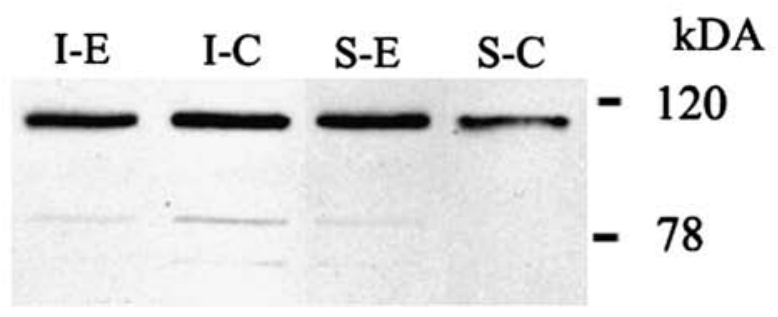

FIG. 2. Surface density measurements of immunohistochemically prepared tissues showed that ischemic insult and EE housing increased the expression of $\beta$ APP N-terminal fragments (A) in the hippocampal area, and this was validated by Western blot band size $(\mathbf{B})\left({ }^{*} p<0.05 ; \mathrm{F}_{(3 / 44)}=8.19\right.$; mean $\left.\pm \mathrm{SEM}\right)(\mathrm{CON}$, control; $\mathrm{EE}$, enriched environment; Isch, ischemia; $\mathrm{I}-\mathrm{E}$, ischemic-enriched environment; I-C, ischemic-control; S-E, sham-enriched environment; S-C, sham-control; NT, N-terminal fragments). 
the CON group $(1094 \pm 201)$, suggesting the reproducibility of the four-vessel occlusion procedure. Moreover, the lack of a significant difference in neuronal degeneration between the two groups suggests that housing animals in the enriched environment 3 days after reperfusion may not have an effect in "rescuing" neurons that are highly vulnerable to ischemia.

\section{$\beta A P P$ expression}

Several studies reported that $\beta$ APP has both beneficial and toxic effects. Substantial evidence has demonstrated the involvement of $\beta \mathrm{APP}$ in the regulation of neuronal growth and survival under normal conditions (Apelt et al., 1997; Huber et al., 1997). Additionally, both in-vivo and in-vitro studies showed that $\beta \mathrm{APP}$ protects neurons against hypoglycemic, excitotoxic, and ischemic damage, suggesting its neuroprotective actions (Bowes et al., 1994; Meziane et al., 1998; SmithSwintosky et al., 1994). Conversely, toxic effects of $\beta$ APP have also been reported (Banati et al., 1995; Kalaria et al., 1993b; Kim et al., 1998; Popa-Wagner et al., 1998; Yam et al., 1997). To determine whether differential expression of $\beta \mathrm{APP}$ fragments results from ischemic injury, we examined the levels of N-terminal (NT) and C-terminal (CT) fragments of secreted $\beta$ APP. Surface density measurements from immunohistochemistry revealed that sham animals housed in EE and both ischemic groups had increased levels of NT- $\beta$ APP compared to the sham control group (Fig. 2A); and band size from the Western blot validated that the antibody used detected NT$\beta$ APP fragments (Fig. 2B). Post-hoc comparisons showed no significant group differences in NT- $\beta$ APP levels between the sham EE animals and rats in both ischemic groups.

Levels of CT- $\beta$ APP and BACE1, on the hand, increased following cerebral ischemia, but not with EE housing alone. That is, increased CT- $\beta$ APP expression (Fig. 3A and B) and BACE1 levels (Fig. 3C) were seen in all ischemic animals compared to the sham groups. No significant differences were seen in CT- $\beta$ APP and BACE1 levels between the sham EE and sham CON groups, whereas comparison of the ischemic groups showed that CT- $\beta$ APP levels in the ischemic CON group were approximately $21 \%$ higher than those in the ischemic EE animals. Furthermore, the pattern of BACE1 expression seen in the ischemic rats was similar to that for CT- $\beta$ APP, suggesting that ischemia possibly enhanced cleavage of the full-length $\beta \mathrm{APP}$ by the $\beta$-secretase complex, thus generating more carboxyl-terminal fragments. Taken together, these data suggest that EE housing has no discernable impact on expression of CT- $\beta$ APP and BACE1 under normal conditions. Pathologic conditions, on the other hand, can trigger increased secretion of CT- $\beta$ APP and BACE1; however, housing rats in EE after ischemia can decrease CT- $\beta$ APP and BACE1 expression. The combined data for NT- $\beta$ APP and CT- $\beta$ APP expression, as well as BACE1 levels, indicate the possibility that both EE housing and cerebral ischemia have direct but diverse effects on $\beta$ APP functioning, in that different processing pathways may be influenced, depending on the animal's physiological or pathological state.

\section{Amyloid burden, oligomerization, and neprilysin expression}

There is substantial evidence suggesting that increased $\beta$ APP expression in cerebral ischemia leads to increased production and accumulation of $\mathrm{A} \beta$. In the present study, we
A
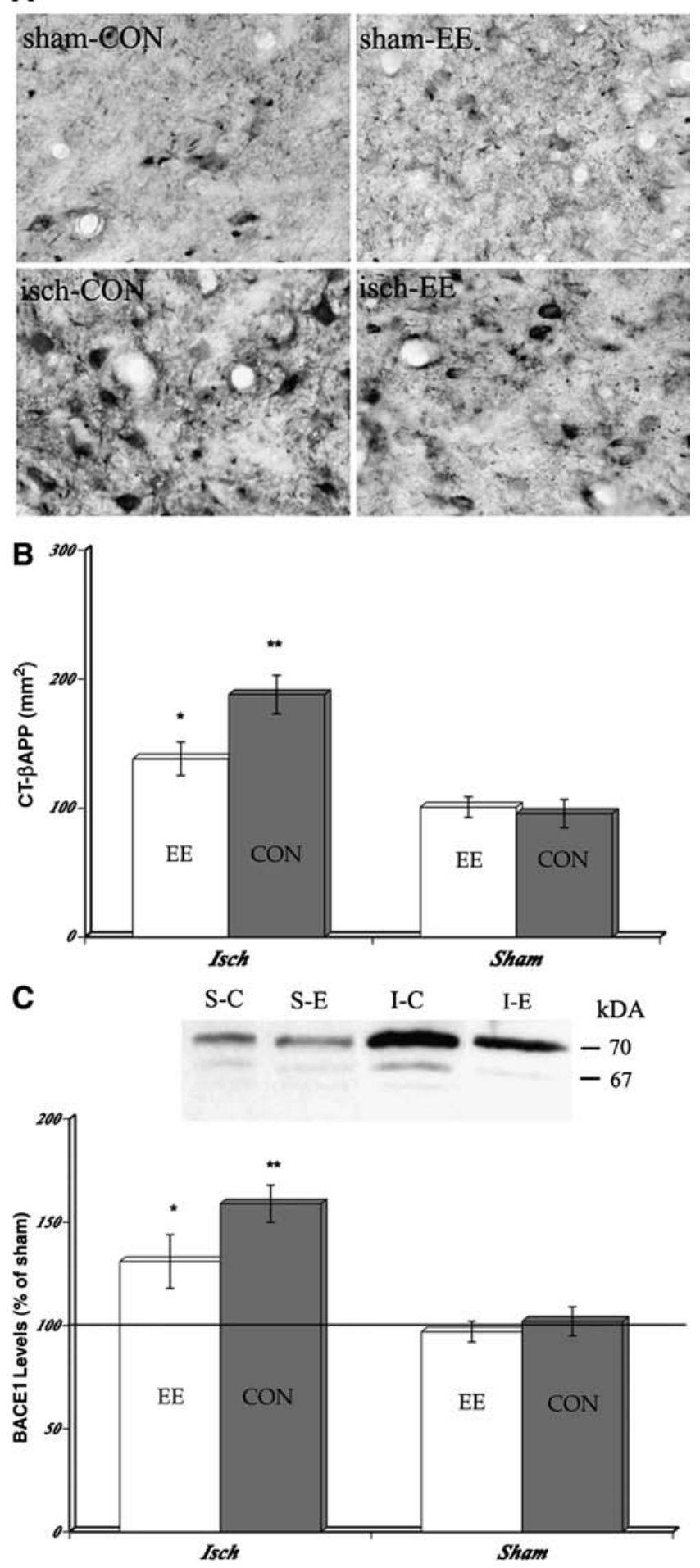

FIG. 3. Representative photomicrographs of $\beta \mathrm{APP} C$ terminal (CT) fragment staining (A). Cerebral ischemia resulted in increased expression of CT- $\beta$ APP fragments, but EE housing after ischemic injury modulated the levels of CT fragments (B). A similar pattern of expression was seen in BACE levels $(\mathbf{C})$. A representative immunoblot of BACE is shown above part $\mathrm{C}\left({ }^{*} p<0.05, \mathrm{~F}_{(3 / 44)}=7.39 ;{ }^{* *} p<0.01\right.$, $\mathrm{F}_{(1 / 46)}=9.19$; mean $\left.\pm \mathrm{SEM}\right)$ (CON, control; $\mathrm{EE}$, enriched environment; isch and Isch, ischemia; I-E, ischemic-enriched environment; I-C, ischemic-control; S-E, sham-enriched environment; S-C, sham-control). 
observed an increase in amyloid load in the ischemic animals compared to the sham animals (Fig. 4A), but providing enrichment during the recovery period after ischemic injury significantly reduced the amyloid burden in the hippocampus. The amyloid load in the hippocampus of ischemic CON rats was approximately $48 \%$ greater than that in the ischemic EE animals, suggesting that environmental enrichment was able to modulate the $\mathrm{A} \beta$ burden (Fig. $4 \mathrm{~A}$ ).

Accumulation of the oligomeric form of $\mathrm{A} \beta$ peptide in the brain is currently considered a major risk factor for the onset of cognitive deficits (Cleary et al., 2005; Klyubin et al., 2005). Our results show that levels of $\mathrm{A} \beta$ oligomers were approximately $43 \%$ less in the ischemic EE rats, compared to the ischemic control group (Fig. 4C). Moreover, the decrease in $\mathrm{A} \beta$ oligomers in the ischemic EE rats coincided with a corresponding increase in monomeric $\mathrm{A} \beta$ peptides and reduction in total amyloid load (Fig. 4). No A $\beta$ oligomerization was seen in the sham animals. These results suggest that the ischemiainduced amyloid burden may be comprised of both oligomeric and monomeric $\mathrm{A} \beta$ peptides, but housing rats in $\mathrm{EE}$ after injury may modulate A $\beta$ peptide oligomerization.

Synthesis and degradation of $\mathrm{A} \beta$ may be an important factor in determining amyloid burden. It has been suggested that accumulation of $\mathrm{A} \beta$ may be explained by a reduction in the catabolic activity of $\mathrm{A} \beta$-degrading enzymes such as NEP, IDE, and endothelin-converting enzymes 1 and 2 (Mouri et al., 2006). To assess the possibility that the reduction in amyloid load seen in the ischemic EE rats is a result of the activation of one of the classical $\mathrm{A} \beta$ degradation pathways, we examined levels of NEP and IDE in the hippocampus. No significant group differences were seen in levels of IDE (data not shown). However, a significant main effect of ischemia was seen in NEP in that ischemic animals demonstrated higher levels compared to the sham rats (Fig. 5). When levels of NEP were compared in the ischemic groups, the ischemic EE rats showed significantly higher levels than the ischemic CON group. No significant group difference was seen in the sham groups. These results suggest that cerebral ischemia increased the activity of the $\mathrm{A} \beta$ degradation pathway mediated by NEP, and that housing rats in EE may lead to decreased $\mathrm{A} \beta$ burden following ischemic injury. It is also possible that in the ischemic $\mathrm{CON}$ rats, the catabolic activity of amyloid-degrading enzymes may be overwhelmed by the increased production of $\mathrm{A} \beta$ so that NEP levels were depleted faster compared to the ischemic EE animals; thus resulting in increased amyloid burden.

\section{Behavioral performance in the water maze}

After ensuring that visual skills were intact, the rats were tested in a series of water maze tasks designed to assess spatial learning and long-term memory of a fixed location. A significant within-subject effect was seen for swim latency across the test days given that all the rats learned to perform the task efficiently over the four testing days. An overall significant main effect of ischemia was also seen in swim latency (Fig. 6A), in that ischemic animals assigned to the CON group demonstrated longer mean swim latency overall compared to all groups. Additionally, a trend toward an interaction effect $\left(\mathrm{F}_{(3 / 44)}=5.78, p<0.06\right)$ was seen between ischemia and $\mathrm{EE}$ in mean swim latency. Meanwhile, comparison of mean swim latency in the sham animal groups did not show significant differences across the test days.
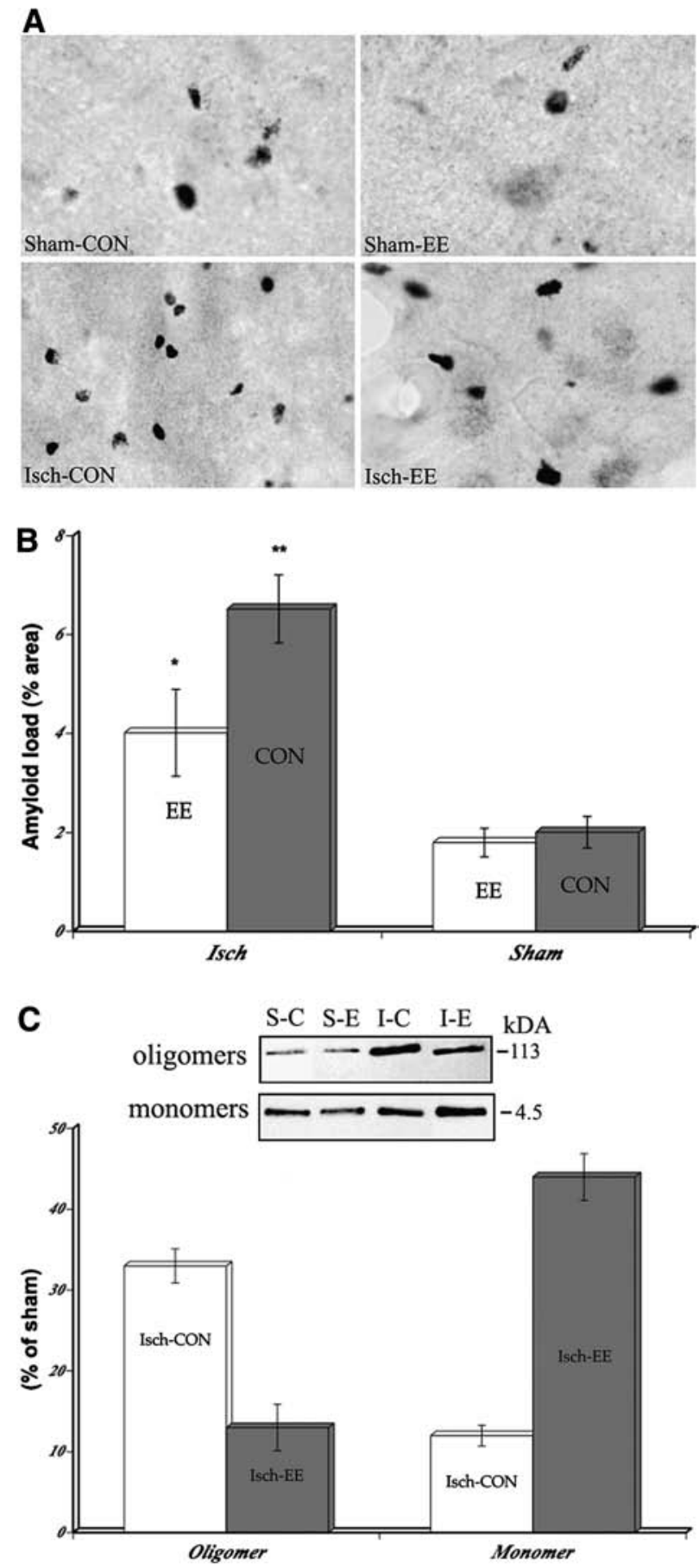

FIG. 4. Representative photomicrographs of amyloid staining (A) showing the atypical plaques consistent with rat $\mathrm{A} \beta$. Amyloid burden increased following cerebral ischemia (B), but EE housing after ischemic injury modulated the amyloid load $\left({ }^{*} p<0.05, \mathrm{~F}_{(5 / 30)}=8.40 ;{ }^{* *} p<0.01, \mathrm{~F}_{(3 / 44)}=\right.$ 11.51). Ischemic injury also resulted in increased levels of both $\mathrm{A} \beta$ oligomers and monomers, but housing rats in $\mathrm{EE}$ after ischemia decreased the oligomerization of the $\mathrm{A} \beta$ peptide (C). Representative immunoblots of oligomers and monomers are shown above part $\mathrm{C}\left({ }^{*} p<0.05, \mathrm{~F}_{(3 / 44)}=8.28\right.$ significantly different from shams; ${ }^{* *} p<0.01, \mathrm{~F}_{(3 / 44)}=12.28$, significantly different overall; mean $\pm \mathrm{SEM}$ ) (CON, control; $\mathrm{EE}$, enriched environment; Isch, ischemia; I-E, ischemicenriched environment; I-C, ischemic-control; S-E, shamenriched environment; S-C, sham-control). 

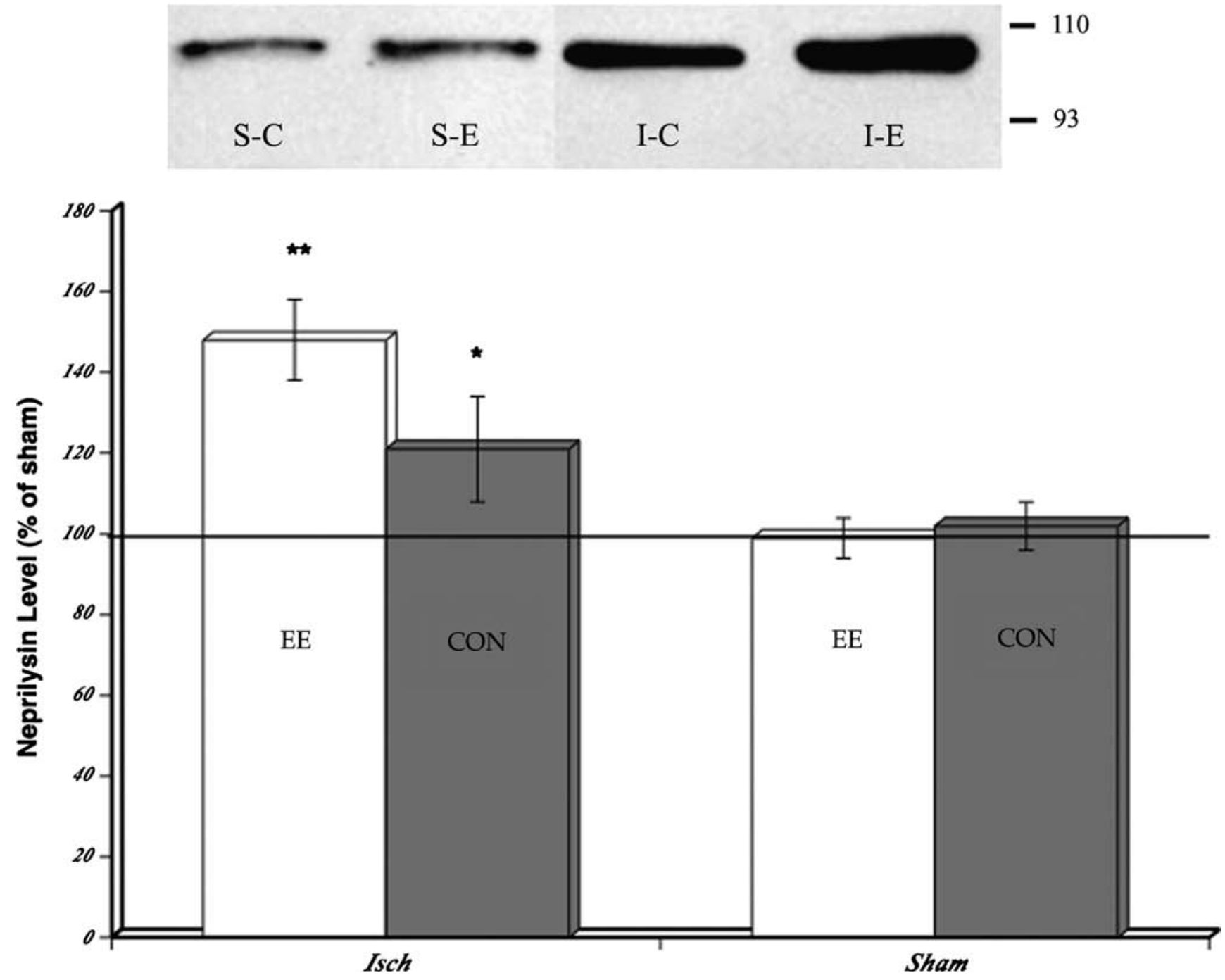

FIG. 5. Cerebral ischemia resulted in increased neprilysin levels, but housing rats in EE after ischemic insult modulated neprilysin depletion $\left({ }^{*} p<0.05, \mathrm{~F}_{(3 / 44)}=8.05 ;{ }^{* *} p<0.01, \mathrm{~F}_{(3 / 44)}=10.02\right.$; mean $\left.\pm \mathrm{SEM}\right)(\mathrm{CON}$, control; EE, enriched environment; Isch, ischemia; I-E, ischemic-enriched environment; I-C, ischemic-control; S-E, sham-enriched environment; S-C, shamcontrol).

Measurement of path length also showed significant within-subject effect in which all rats showed a continuous decrease in the swimming distance covered to reach the platform across the test days. An overall significant main effect of ischemia was seen in which the ischemic CON animals frequently used the indirect path to reach the goal compared to all groups (Fig. 6B). More importantly, a significant interaction effect was seen between ischemia and EE housing in mean path length $\left(\mathrm{F}_{(3 / 44)}=8.90, p<0.05\right)$, in which the ischemic EE rats performed as well as the sham animals across the test days. Comparison of path length in the sham groups showed no significant differences. Furthermore, comparison of swimming speed did not show significant group differences. Taken together, the swim latency and path length results suggest that the rats were able to determine their location in space, and adjust their behavior accordingly, suggesting some degree of spontaneous functional recovery; however, housing ischemic rats in EE may help enhance this spontaneous recovery.

On the fifth day of behavioral testing, a probe trial was performed for $60 \mathrm{sec}$ wherein rats were placed in the water maze without the goal platform. Time spent swimming in the quadrant of the pool where the goal platform was located during the first 4 days of the trial (correct quadrant) was divided by the time spent swimming in the other 3 quadrants of the pool (wrong quadrants). In the probe trial (longterm memory recall phase) a significant difference was seen (Table 1), in that the ischemic CON animals spent less time in the correct target quadrant area where the goal was previously located and made more search errors compared to all groups. On the contrary, the performance of the ischemic EE rats in the probe trial was indistinguishable from that of 
A

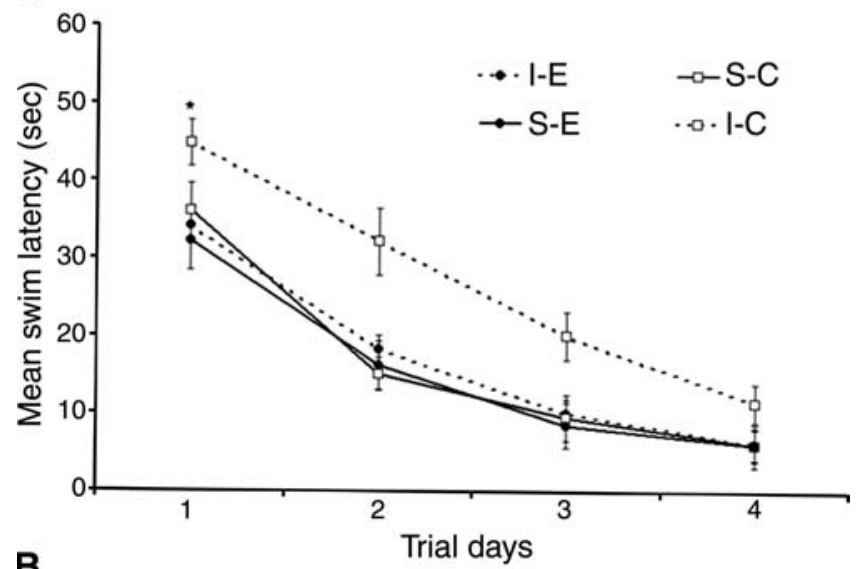

B

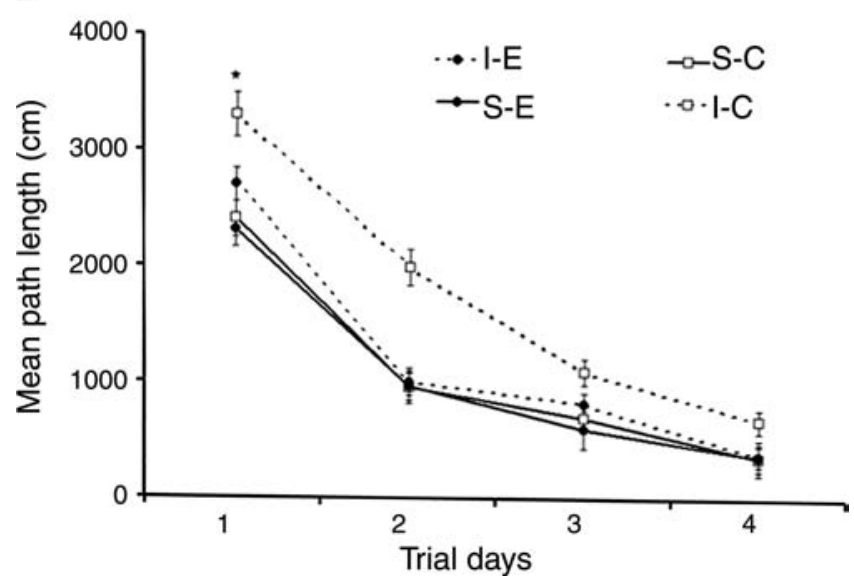

FIG. 6. Increased mean swim latency (A) and path length taken (B) was seen in the ischemic control animals compared to all the groups. Ischemic rats housed in EE performed as well as the shams in the behavioral task ${ }^{*} p<0.05, \mathrm{~F}_{(3 / 44)}=$ 9.11) for swim latency $\left(\mathrm{F}_{(3 / 44)}=9.50\right)$ and for path length (mean \pm SEM) (I-E, ischemic-enriched environment; I-C, ischemic-control; S-E, sham-enriched environment; S-C, sham-control).

the sham groups, suggesting that the ischemia-induced persistent memory impairment may be diminished by environmental enrichment.

\section{Discussion}

In the present study, we show that EE housing after cerebral ischemic injury significantly decreased the expression of the cytotoxic fragment of $\beta \mathrm{APP}$, reduces $\mathrm{A} \beta$ load and oligomerization of the $\mathrm{A} \beta$ peptide, increased the levels of NEP, and enhanced behavioral recovery. $\beta \mathrm{APP}$ is a transmembrane protein with a long extracellular $\mathrm{N}$-terminal and short intracellular C-terminal domain. $\beta$ APP is widely expressed in the brain, where its abnormal upregulation can lead to the accumulation of $\mathrm{A} \beta$. Although it is possible that ischemia-induced accumulation of $\mathrm{A} \beta$ may be partly responsible for the loss of pyramidal neurons in the CA1 subfield of the hippocampus because of the peptide's ability to induce oxidative damage (reviewed in Perry et al., 2002), this is not supported by the findings in the present study. Our results show that the degree of cell loss in the CA1 subfield between the two
Table 1. Behavioral Measures in the Probe Trial

\begin{tabular}{lcc}
\hline Groups & $\begin{array}{c}\text { Time spent } \\
\text { in correct } \\
\text { quadrant }(\%)\end{array}$ & $\begin{array}{c}\text { Number of search } \\
\text { errors made during } \\
\text { the trial }\end{array}$ \\
\hline Ischemic EE & $59 \pm 3.13$ & $1.66 \pm 0.19$ \\
Ischemic CON & $* 34 \pm 4.02$ & $2.8 \pm 0.14$ \\
Sham EE & $63 \pm 3.86$ & $1.44 \pm 0.17$ \\
Sham CON & $66 \pm 3.45$ & $1.78 \pm 0.22$ \\
\hline
\end{tabular}

Ischemic control rats made more mistakes compared to all groups, while the ischemic EE rats performed as well as the sham groups $\left(\right.$ mean \pm SEM, $\left.{ }^{*} p<0.05, \mathrm{~F}_{(3 / 44)}=8.77\right)$.

ischemic groups are similar despite significant differences in amyloid load, and that the ischemic EE rats had lower levels than the ischemic CON rats. These results indicate that other mechanisms such as calcium-mediated glutamate excitotoxicity (Wahl et al., 2008) may be either directly or indirectly responsible for the neurodegeneration seen in the ischemic animals. But a more likely explanation is that when EE housing was implemented in the present study, ischemiainduced delayed neuronal death may have already occurred, particularly in the brain region most vulnerable to ischemic insult.

Our data demonstrate an EE-induced reduction in $\mathrm{A} \beta$ burden after ischemic insult, which parallels those of others that show decreased amyloid deposition after enriched housing (Lazarov et al., 2005) in a transgenic mouse model of Alzheimer's disease (AD). Whether enrichment is given in the form of novelty sessions (Lazarov et al., 2005) or use of continuous housing as in the present study, the effectiveness of environmental enrichment in reducing $\mathrm{A} \beta$ load is similar. In the present study, one possible mechanism that might account for the EE-induced reduction in $\mathrm{A} \beta$ load after cerebral ischemia may be related to the modulation of BACE1 and CT- $\beta$ APP fragment release. Because BACE1 is the major secretase enzyme responsible for cleaving the $\beta$ APP ectodomain to generate a C-terminus fragment, it stands to reason that a reduction in BACE1 level may then lead to decreased expression of CT- $\beta$ APP and a subsequent reduction in amyloid burden.

Since our data demonstrate that the NEP level but not IDE is elevated in the hippocampus of ischemic rats housed in EE compared to the ischemic CON animals or sham groups, it is possible that another mechanism underlying the EE-induced reduction in $\mathrm{A} \beta$ involves the activity of certain $\mathrm{A} \beta$-degrading protease. Our findings are consistent with several in-vivo studies that demonstrate that ectopic overexpression of NEP in the brains of $\mathrm{AD}$ mouse models leads to the reduction in $\mathrm{A} \beta$ deposition and clearance of preexisting $\mathrm{A} \beta$ deposits (Iwata et al., 2004; Marr et al., 2003). NEP is capable of degrading the monomeric as well as the oligomeric forms of $\mathrm{A} \beta$ (Kanemitsu et al., 2003). Further support for the role of neprilysin in amyloid degradation is shown in a study that demonstrates increased $\mathrm{A} \beta$ accumulation in the hippocampus of rats that received thiorpan, a NEP inhibitor, infusion through the cerebral ventricles (Mouri et al., 2006). Therefore our study and those of others provide confirmation that NEP participates in the catabolism of $\mathrm{A} \beta$ in the brain, but the mechanism of how EE housing can increase NEP activity remains unclear. 
The lack of a significant difference seen in the levels of IDE is puzzling. IDE is a small protein, $\sim 110 \mathrm{kDa}$ in size, that is a thiol zinc-metalloendopeptidase. IDE preferentially cleaves insulin, but it also cleaves other small proteins such as $\mathrm{A} \beta$. The role of IDE in $\mathrm{A} \beta$ degradation is demonstrated in studies that show that genetic deletion of this protease in mice brains leads to excess amyloid accumulation (Farris et al., 2003; Miller et al., 2003). But in the present study, IDE did not have an effect on decreasing amyloid burden. A likely explanation for this lack of significance is that IDE's effects on $\mathrm{A} \beta$ may be nonspecific.

Another possible mechanism of EE-induced reduction in $\mathrm{A} \beta$ involves alteration in $\beta \mathrm{APP}$ functioning. Our results show increased expression of NT- $\beta$ APP in both ischemic groups and in sham animals housed in EE, while increased CT- $\beta$ APP expression was seen only in the ischemic groups. Our $\beta$ APP results seen in sham animals housed in EE are hardly surprising since the enrichment paradigm is shown to induce plasticity-related events such as synaptogenesis and neurogenesis (Briones et al., 2004a; van Praag et al., 2000; West and Greenough, 1972), and NT- $\beta$ APP is reported to be involved in the regulation of neuronal growth and survival (Mattson, 1997; Selkoe et al., 1997). NT- $\beta$ APP is also implicated in potentiating the neurotrophic properties of growth factors via telomerase activity (an enzyme that is required for the long-term survival of post-mitotic neurons) (Fu et al., 2002). We also demonstrate an increase in NT- $\beta$ APP following cerebral ischemia, and these findings are similar to those of others (Badan et al., 2004; Banati et al., 1995; Kalaria et al., 1993b; Popa-Wagner et al., 1998), and may be indicative of a compensatory response to protect the brain from ischemic insult, since NT- $\beta$ APP appears to have growth-supporting properties.

The ischemia-induced increase in CT- $\beta$ APP expression seen in the present report is also in line with results of other studies (Badan et al., 2004; Kim et al., 1998; Popa-Wagner et al., 1998). It is believed that the generation of CT- $\beta$ APP is a pathological event because these fragments can promote synaptic degeneration and neuronal death (Qiao et al., 2001) by increasing the production of $\mathrm{A} \beta$ (Kim et al., 1998). More recent work shows that CT- $\beta$ APP induces the death of astrocytes, whereas the loss of neurons is a secondary consequence of the neuronal dependence on astrocytes for antioxidant protection (Abramov et al., 2003). Of possible relevance is our finding that the level of CT- $\beta$ APP is significantly lower in the ischemic EE rats in relation to the ischemic CON animals. Since we previously demonstrated that EE housing after cerebral ischemia increased the surface density of astrocytic processes in the hippocampus (Briones et al., 2006c), it is possible that the protective effects of enrichment against the toxic effects of CT- $\beta$ APP may be mediated by astrocytes. These data on C-terminal and N-terminal fragments when taken together suggest that cerebral ischemia can directly influence $\beta \mathrm{APP}$ functioning, and that environmental enrichment strongly modulates the amyloidogenic pathway (an explanation also supported by data on BACE1 levels), decreasing the likelihood of release of the $\mathrm{A} \beta$-bearing $\mathrm{CT}$ fragment, thereby reducing amyloid load.

Interestingly, our findings on $\mathrm{A} \beta$ load are in conflict with earlier studies that reported an increased amyloid burden after housing in an AD mouse model of EE (Jankowsky et al., 2005; Jankowsky et al., 2003). Meanwhile, other investigators reported no effects of environmental enrichment on amyloid burden (Arendash et al., 2004; Costa et al., 2007) in the AD mouse model. It is important to point out that there is a difference between these AD mouse model studies and the present study in that either female mice were placed in EE (Jankowsky et al., 2005; Jankowsky et al., 2003), or both male and female mice were housed together in the enriched environment (Arendash et al., 2004; Costa et al., 2007), while in the present report we used only male rats. Incidentally, there is a documented gender difference in $\mathrm{A} \beta$ deposition in $\mathrm{AD}$, in which females usually have more amyloid load compared to age-matched males (Wang et al., 2003). It should also be noted that even though an EE-induced exacerbation in $\mathrm{A} \beta$ load has been reported in the earlier AD mouse model study (Jankowsky et al., 2003), some of the animals in the EE group showed lower $\mathrm{A} \beta$ levels than did the controls.

In the present study, the acquisition of memory (the first 4 days of testing) is conceptually distinguished from the ability to recall this memory at a later time point (probe trial). The steep learning curves in Figure 6 reflect the memory acquisition phase and how fast the animals learned the task. Even though all animals learned the task, our data show that memory impairment remains post-ischemic injury, but that housing rats in EE after ischemia may improve these cognitive deficits. It is important to note that the cognitive impairment in the ischemic $\mathrm{CON}$ rats seen during the early days of the trials was not related to deficits in motor function, since swimming speed, that measured motor activity, did not show significant group differences. These behavioral findings suggest that learning a simple task can occur, even if most of the hippocampal neurons were damaged; however, consolidation of learned information will likely be impaired. Our results on improved cognitive performance in the ischemic EE group in both the acquisition and recall phase of testing are consistent with those of earlier studies that demonstrated enhanced functional recovery when ischemic rats are housed in EE (Briones et al., 2000; Briones et al., 2006b; Puurunen et al., 2001; Puurunen et al., 1997). It is possible that the memory improvement seen in the ischemic EE group may be attributed to water maze testing and not the EE-induced $\mathrm{A} \beta$ reduction alone. But the fact that the ischemic CON rats showed impairment in the probe trial relative to the ischemic EE animals suggests that the improvement in memory deficits seen in this study are primarily due to the effects of enrichment. However, it is likely that the combination of EE housing after ischemia and behavioral testing may have profound effects in lowering A $\beta$ levels, specifically the oligomeric form. Since both ischemic groups demonstrated increased amyloid load in comparison to the sham rats, the dramatic attenuation of cognitive impairment seen in the ischemic EE animals may be attributed to the decreased $\mathrm{A} \beta$ oligomerization. This line of reasoning is supported by studies indicating that extracellular accumulation of $\mathrm{A} \beta$ oligomers is largely responsible for the memory deficits seen in the AD mouse model (Cleary et al., 2005; Klyubin et al., 2005). In the present study, it is not possible to distinguish the independent effects of EE housing and behavioral testing on $\mathrm{A} \beta$ reduction and cognitive improvement, but it is important to examine this notion at a later date.

An unexpected finding in our behavioral data is the lack of significant differences in the performance of the sham EE and sham CON animals in both the acquisition and recall phases in the water maze. These findings are at odds with others that demonstrate better performance in the radial arm maze, water 
maze, and Hebb-Williams maze among normal rats housed in EE (Kobayashi et al., 2002; Leggio et al., 2005; Paganelli et al., 2004; Pham et al., 1999; Schrijver et al., 2004). A possible explanation for this difference in findings is that the place learning task in the water maze may lack sufficient complexity to detect subtle learning differences in normal animals, thus performance of both sham groups will likely be affected by a "ceiling effect." But a more likely reason is that our behavioral results in the sham animals may have been confounded by the cued-platform trials given before behavioral testing.

In sum, the present experiments provide evidence that housing rats in EE after cerebral ischemia modifies $\beta \mathrm{APP}$ functioning by reducing the accumulation of $C$-terminal stubs that can increase $\mathrm{A} \beta$ production. Also, evidence that CT- $\beta$ APP fragments decreased while NEP levels increased in the ischemic EE animals provides further support for the view that enrichment has $\mathrm{A} \beta$-lowering properties. The relationship between an EE-induced increase in NEP levels and improvement in memory performance indirectly points to the importance of using $\mathrm{A} \beta$-lowering strategies in mitigating amyloid-induced cognitive impairment. Specifically, the use of EE after cerebral ischemia may be a cost-effective strategy to modulate the oligomerization of $\mathrm{A} \beta$ peptides and promote functional recovery. Lastly, the increase in NT- $\beta$ APP seen in the EE-housed sham rats provides further support for its role in neural plasticity.

\section{Acknowledgments}

This work was supported by the National Institutes of Health, NINR grant no. RO1 NR007666. We are grateful for the assistance of Maggie Wadowska in animal handling and tissue imaging. We would also like to thank Mai Nguyen for assistance in the analysis of behavioral data.

\section{Author Disclosure Statement}

No competing financial interests exist for all authors.

\section{References}

Abramov, A.Y., Canevari, L., and Duchen, M.R. (2003). Changes in intracellular calcium and glutathione in astrocytes as the primary mechanism of amyloid neurotoxicity. J. Neurosci. 23, 5088-5095.

Apelt, J., Schliebs, R., Beck, M., Robner, S., and Bigl, V. (1997). Expression of amyloid precursor protein mRNA isoforms in rat brain is differentially regulated during postnatal maturation and by cholinergic activity. Int. J. Dev. Neurosci. 15, 95-112.

Arendash, G.W., Garcia, M.F., Costa, D.A., Cracchiolo, J.R., Wefes, I.M., and Potter, H. (2004). Environmental enrichment improves cognition in aged Alzheimer's transgenic mice despite stable beta-amyloid deposition. NeuroReport 15, 1751-1754.

Badan, I., Dinca, I., Buchhold, B., Suofu, Y., Walker, L.C., Gratz, M., Platt, D., Kessler, C., and Popa-Wagner, A. (2004). Accelerated accumulation of $\mathrm{N}$ - and $\mathrm{C}$-terminal bAPP fragments and delayed recovery of microtubule-associated protein $1 \mathrm{~B}$ expression following stroke in aged rats. Eur. J. Neurosci. 19, 2270-2280.

Banati, R.B., Gehrmann, J., Wiebner, C., Hossmann, K.A., and Kreutzberg, G.W. (1995). Glial expression of the beta-amyloid precursor protein (APP) in global ischemia. J. Cereb. Blood Flow Metab. 15, 647-654.
Bhatia, P., Taylor, W.R., Greenberg, A.H., and Wright, J.A. (1994). Comparison of glyceraldehyde-3-phosphate dehydrogenase and 28S-ribosomal RNA gene expression as RNA loading controls for northern blot analysis of cell lines of varying malignant potential. Anal. Biochem. 216, 223-226.

Bouët, V., Freret, T., Toutain, J., Divoux, D., Boulouard, M., and Schumann-Bard, P. (2007). Sensorimotor and cognitive deficits after transient middle cerebral artery occlusion in the mouse. Exp. Neurol. 203, 555-567.

Bowes, M.P., Masliah, E., Otero, D.A., Zivin, J.A., and Saitoh, T. (1994). Reduction of neurological damage by a peptide segment of the amyloid beta/A4 protein precursor in a rabbit spinal cord ischemia model. Exp. Neurol. 129, 112-119.

Briones, T.L., Klintsova, A.Y., and Greenough, W.T. (2004a). Stability of synaptic plasticity in the adult rat visual cortex induced by complex environment exposure. Brain Res. 1018, 130-135.

Briones, T.L., Suh, E., Hattar, H., and Wadowska, M. (2005). Dentate gyrus neurogenesis after cerebral ischemia and behavioral training. Biol. Res. Nurs. 6, 167-179.

Briones, T.L., Suh, E., Jozsa, L., and Woods, J. (2006a). Behaviorally induced synaptogenesis and dendritic growth in the hippocampal region following transient global cerebral ischemia are accompanied by improvement in spatial learning. Exp. Neurol. 198, 530-538.

Briones, T.L., Suh, E., Jozsa, L., Hattar, H., Chai, J., and Wadowska, M. (2004b). Behaviorally-induced ultrastructural plasticity in the hippocampal region after cerebral ischemia. Brain Res. 997, 137-146.

Briones, T.L., Therrien, B., and Metzger, B. (2000). Effects of environment on enhancing functional plasticity following cerebral ischemia. Biol. Res. Nurs. 1, 299-309.

Briones, T.L., Woods, J., Wadowska, M., and Rogozinska, M. (2006b). Amelioration of cognitive impairment and changes in microtubule-associated protein 2 after transient global cerebral ischemia are influenced by complex environment experience. Behav. Brain Res. 168, 261-271.

Briones, T.L., Woods, J., Wadowska, M., Rogozinska, M., and Nguyen, M. (2006c). Astrocytic changes in the hippocampus and functional recovery after cerebral ischemia are facilitated by rehabilitation training. Behavioural Brain Res. 171, 17-25.

Chen, X., Li, Y., Kline, A.E., Dixon, C.E., Zafonte, R.D., and Wagner, A.K. (2005). Gender and environmental effects on regional brain-derived neurotrophic factor expression after experimental traumatic brain injury. Neuroscience 135, 11-17.

Cleary, J.P., Walsh, D.M., Hofmeister, J.J., Shankar, G.M., Kuskowski, M.A., Selkoe, D.J., and Ashe, K.H. (2005). Natural oligomers of the amyloid-beta protein specifically disrupts cognitive function. Nat. Neurosci. 8, 79-84.

Costa, D.A., Cracchiolo, J.R., Bachstetter, A.D., Hughes, T.F., Bales, K.R., Paul, S.M., Mervise, R.F., Arendash, G.W., and Potter, H. (2007). Enrichment improves cognition in AD mice by amyloid-related and unrelated mechanisms. Neurobiol. Aging 28, 831-844.

Davidson, C.M., Pappas, B.A., Stevens, W.D., Fortin, T., and Bennett, S.A. (2000). Chronic cerebral hypoperfusion: loss of pupillary reflex, visual impairment and retinal neurodegeneration. Brain Res. 859, 96-103.

Escorihuela, R.M., Fernandez-Tereul, A., Tobena, A., and Vivas, N.M. (1995). Early environmental stimulation produces longlasting changes on b-adrenoceptor transduction. Neurobiol. Learn. Mem. 64, 49-57.

Farris, W., Mansourian, S., Chang, Y., Lindsley, L., Eckman, E.A., Frosch, M.P., Eckman, C.B., Tanzi, R.E., Selkoe, D.J., and 
Guenette, S. (2003). Insulin-degrading enzyme regulates the levels of insulin, amyloid beta-protein, and beta-amyloid precursor protein intracellular domain in vivo. Proc. Natl. Acad. Sci. U.S.A. 100, 4162-4167.

$\mathrm{Fu}$, W., Lu, C., and Mattson, M.P. (2002). Telomerase mediates the cell survival-promoting actions of brain-derived neurotrophic factor and secreted amyloid precursor protein in developing hippocampal neurons. J. Neurosci. 22, 1071010719.

Gaulke, L.J., Horner, P.J., Fink, A.J., McNamara, C.L., and Hicks, R.R. (2005). Environmental enrichment increases progenitor cell survival in the dentate gyrus following lateral fluid percussion injury. Brain Res. Mol. Brain Res. 141, 138-150.

Greenough, W.T., and Volkmar, F.R. (1973). Pattern of dendritic branching in occipital cortex of rats reared in complex environment. Exp. Neurol. 40, 491-504.

Hicks, R.R., Zhang, L., Atkinson, A., Stevenon, M., Veneracion, M., and Seroogy, K.B. (2002). Environmental enrichment attenuates cognitive deficits, but does not alter neurotrophin gene expression in the hippocampus following lateral fluid percussion brain injury. Neuroscience 112, 631-637.

Huber, G., Bailly, Y., Martin, J.R., Mariani, J., and Brugg, B. (1997). Synaptic beta-amyloid precursor proteins increase with learning capacity in rats. Neuroscience 80, 313-320.

Ishimaru, H., Ishikawa, K., Haga, S., Shoji, M., Ohe, Y., Haga, C., Sasaki, A., Takashashi, A., and Maruyama, Y. (1996). Accumulation of apolipoprotein $\mathrm{E}$ and beta-amyloid-like-protein in a trace of the hippocampal CA1 pyramidal layer after ischeaemic delayed neuronal death. Neuroreport 7, 3063-3067.

Iwata, N., Mizukami, H., Shirotani, K., Takaki, Y., Muramatsu, S., Lu, B., Gerard, N.P., Gerard, C., Ozawa, K., and Saido, T.C. (2004). Presynaptic localization of neprilysin contributes to efficient clearance of amyloid-beta peptide in mouse brain. J. Neurosci. 24, 991-998.

Jankowsky, J.L., Melnikova, T., Fadale, D.J., Xu, G.M., Slunt, H.H., Gonzales, V., Younkin, L.H., Younkin, S.G., Borchelt, D.R., and Savonenko, A.V. (2005). Environmental enrichment mitigates cognitive deficits in a mouse model of Alzheimer's disease. J. Neurosci. 25, 5217-5224.

Jankowsky, J.L., Xu, G., Fromholt, D., Gonzales, V., and Borchelt, D.R. (2003). Environmental enrichment exacerbates amyloid plaque formation in a transgenic mouse model of Alzheimer disease. J. Neuropathol. Exp. Neurol. 62, 1220-1227.

Jones, T.A., and Schallert, T. (1992). Overgrowth and pruning of dendrites in adult rats recovery from neocortical damage. Brain Res. 581, 156-160.

Kalaria, R.N., Bhatti, S.U., Lust, W.D., and Perry, G. (1993a). The amyloid precursor protein in ischemia brain injury and chronic hypoperfusion. Ann. N.Y. Acad. Sci. 695, 190-193.

Kalaria, R.N., Bhatti, S.U., Palatinsky, E.A., Pennington, D.H., Shelton, E.R., Chan, H.W., Perry, G., and Lust, W.D. (1993b). Accumulation of the beta-amyloid precursor protein at sites of ischemic injury in rat brain. NeuroReport 4, 211-214.

Kamenetz, F., Tomita, T., Hsieh, H., Seabrook, G., Borchelt, D.R., Iwatsubo, T., Sisodia, S.S., and Malinow, R. (2003). APP processing and synaptic function. Neuron 37, 925-937.

Kanemitsu, H., Tomiyama, T., and Mori, T. (2003). Human neprilysin is capable of degrading amyloid $b$ peptide not only in the monomeric form but also in the pathological oligomeric form. Neurosci. Lett. 350, 113-116.

Kim, H.-S., Lee, S.H., Kim, S.S., Kim, Y.K., Jeong, S.J., Ma, J., Han, D.H., Cho, B.K., and Suh, Y.H. (1998). Post-ischemic changes in the expression of Alzheimer's APP isoforms in rat cerebral cortex. NeuroReport 9, 533-537.
Kirino, T. (2000). Delayed neuronal death. Neuropathology 20, S95-S97.

Klyubin, I., Walsh, D.M., Lemere, C.A., Cullen, W.K., Shankar, G.M., Betts, V., Spooner, E.T., Jiang, L., Anwyl, R., Selkoe, D.J., and Rowan, M.J. (2005). Amyloid beta protein immunotherapy neutralizes Abeta oligomers that disrupt synaptic plasticity in vivo. Nat. Med. 11, 556-561.

Kobayashi, S., Ohashi, Y., and Ando, S. (2002). Effects of enriched environments with different durations and starting times on learning capacity during aging in rats assessed by a refined procedure of the Hebb-Williams maze task. J. Neurosci. Res. 70, 340-346.

Lazarov, O., Robinson, J., Tang, Y.-P., Hairston, I.S., KoradeMirnics, Z., Lee, V. M.-Y., Hersh, L.B., Sapolsky, R.M., Mirnics, K., and Sisodia, S.S. (2005). Environmental enrichment reduces Abeta levels and amyloid deposition in transgenic mice. Cell 120, 701-713.

Leggio, M.G., Mandolesi, L., Federico, F., Spirito, F., Ricci, B., Gelfo, F., and Petrosini, L. (2005). Environmental enrichment promotes improved spatial abilities and enhanced dendritic growth in the rat. Behav. Brain Res. 163, 78-90.

Marr, R.A., Rocketstein, E., Mukherjee, A., Kindy, M.S., Hersh, L.B., Gage, F.H., Verma, I.M., and Masliah, E. (2003). Neprilysin gene transfer reduces human amyloid pathology in transgenic mice. J. Neurosci. 23, 1992-1996.

Mattson, M.P. (1997). Cellular actions of beta-amyloid precursor protein and its soluble and fibrillogenic derivatives. Physiol. Rev. 77, 1081-1132.

Meziane, H., Dodart, J.C., Mathis, C., Little, S., Clemens, J., Paul, S.M., and Ungerer, A. (1998). Memory-enhancing effects of secreted forms of the beta-amyloid precursor protein in normal and amnestic mice. Proc. Natl. Acad. Sci. U.S.A. 95, 1268312688.

Miller, B.C., Eckman, E.A., Sambamurti, K., Dobbs, N., Chow, K.M., Eckman, C.B., Hersh, L.B., and Thiele, D.L. (2003). Amyloid-beta peptide levels in brain are inversely correlated with insulysin activity levels in vivo. Proc. Natl. Acad. Sci. U.S.A. 100, 6221-6226.

Mouri, A., Zou, L.-B., Iwata, N., Saido, T.C., Wang, D., Wang, M.-W., Noda, Y., and Nabeshima, T. (2006). Inhibition of neprilysin by thiorphan (i.c.v.) causes an accumulation of amyloid-b and impairment of learning and memory. Behav. Brain Res. 168, 83-91.

Nihashi, T., Inao, S., Kajita, Y., Kawai, T., Sugimoto, T., Niwa, M., Kabeya, R., Hata, N., Hayashi, S., and Yoshida, J. (2001). Expression and distribution of beta amyloid precursor protein and beta amyloid peptide in reactive astrocytes after transient middle cerebral artery occlusion. Acta Neurochirurgica (Wein) 143, 287-295.

Paganelli, R.A., Benetolli, A., Lima, K.C.M., Cestari-Junior, L.A., Favero Filho, L.A., and Milani, H. (2004). A novel version of the 8-arm radial maze: effects of cerebral ischemia on learning and memory. J. Neurosci. Methods 132, 9-18.

Passineau, M.J., Green, E.J., and Dietrich, W.D. (2001). Therapeutic effects of environmental enrichment on cognitive function and tissue integrity following severe traumatic brain injury in rats. Exp. Neurol. 168, 373-384.

Perry, G., Nunomura, A., Hirai, K., Zhu, X., Perez, M., and Avila, J. (2002). Is oxidative damage the fundamental pathogenic mechanism of Alzheimer's and other neurodegenerative diseases? Free Rad. Biol. Med. 33, 1475-1479.

Pham, T.M., Ickes, B., Albeck, D., Söderström, S., Granholm, A.C., and Mohammed, A.H. (1999). Changes in brain nerve growth factor levels and nerve growth factor receptors in rats 
exposed to environmental enrichment for one year. Neurosci. Lett. 94, 279-286.

Pluta, R. (2002). Astroglial expression of the beta-amyloid in ischemia-reperfusion brain injury. Ann. N.Y. Acad. Sci. 977, 102-108.

Popa-Wagner, A., Schröder, E., Walker, L.C., and Kessler, C. (1998). Beta-amyloid precursor protein and beta-amyloid peptide immunoreactivity in the rat brain after middle cerebral artery occlusion. Stroke 29, 2196-2202.

Puurunen, K., Jolkkonen, J., Sirvio, J., Haapalinna, A., and Sivenius, J. (2001). Selegiline combined with enrichedenvironment housing attenuates spatial learning deficits following focal cerebral ischemia in rats. Exp. Neurol. 167, 348-355.

Puurunen, K., Sirvio, J., Koistinaho, J., Miettinen, R., Haapalinna, A., Riekkinen, P., Sr., and Sivenius, J. (1997). Studies on the influence of enriched-environment housing combined with systemic administration of an a2-adrenergic antagonist on spatial learning and hyperactivity after global ischemia in rats. Stroke 28, 623-631.

Qiao, X., Cummins, D.J., and Paul, S.M. (2001). Neuroinflammation-induced acceleration of amyloid deposition in the APPV717F transgenic mice. Eur. J. Neurosci. 14, 474-482.

Schrijver, N.C.A., Pallier, P.N., Brown, V.J., and Wurbel, H. (2004). Double dissociation of social and environmental stimulation on spatial learning and reversal learning in rats. Behav. Brain Res. 152, 307-314.

Selkoe, D.J., Yamazaki, T., Citron, M., Podlisny, M.B., Koo, E.H., Teplow, D.B., and Haass, C. (1997). The role of APP processing and trafficking pathways in the formation of amyloid beta-protein. Ann. N.Y. Acad. Sci. 777, 57-64.

Smith, D.H., Chen, X.H., Iwata, A., and Graham, D.I. (2003). Amyloid beta accumulation in axons after traumatic brain injury in humans. J. Neurosurg. 98, 1072-1077.

Smith-Swintosky, V.L., Pettigrew, L.C., Craddock, S.D., Culwell, A.R., Rydel, R.E., and Mattson, M.P. (1994). Secreted forms of beta-amyloid precursor protein protect against ischemic brain injury. J. Neuorchem. 63, 781-784.

Thellin, O., Zorzi, W., Lakaye, B., De Borman, B., Coumans, B., Hennen, G., Grisar, T., Igout, A., and Heinen, E. (1999).
Housekeeping genes as internal standards: use and limits. J. Biotech. 75, 291-295.

van Praag, H., Kempermann, G., and Gage, F.H. (2000). Neural consequences of environmental enrichment. Nat. Rev. Neurosci. 1, 191-198.

Wagner, A.K., Chen, X., Kline, A.E., Li, Y., Zafonte, R.D., and Dixon, C.E. (2005). Gender and environmental enrichment impact dopamine transporter expression after traumatic brain injury. Exp. Neurol. 195, 475-483.

Wahl, A.S., Buchthal, B., Rode, F., Bomholt, S.F., Freitag, H.E., Hardingham, G.E., Rønn, L.C., and Bading, H. (2008). Hypoxic/ischemia conditions induce expression of the prodeath gene $\mathrm{ClCa} 1$ via activation of extrasynaptic N-methyl-Daspartate receptors. Neuroscience MID: 18616988.

Wang, J., Tanila, H., Puolivali, J., Kadish, I., and Groen, T. (2003). Gender differences in the amount and deposition of amyloid beta in APPswe and PS1 double transgenic mice. Neurobiol. Dis. 14, 318-327.

Wen, Y., Onyewuchi, O., Yang, S., Liu, R., and Simpkins, J.W. (2004). Increased $\beta$-secretase activity and expression in rats following transient cerebral ischemia. Brain Res. 1009, 1-8.

West, R.W., and Greenough, W.T. (1972). Effect of environmental complexity on cortical synapses of rats: preliminary results. Behavior Biol. 7, 279-284.

Yam, P.S., Takasago, T., Dewar, D., Graham, D.I., and McCulloch, J. (1997). Amyloid precursor protein accumulates in white matter at the margin of a focal ischemic lesion. Brain Res. 760, 150-157.

Yi, J.S., Kim, T.Y., Kyu Kim, D., and Koh, J.Y. (2007). Systemic pyruvate administration markedly reduces infarcts and motor deficits in rat models of transient and permanent focal cerebral ischemia. Neurobiol. Dis. 26, 94-104.

Address reprint requests to: Teresita L. Briones, Ph.D. University of Illinois at Chicago

845 S. Damen Avenue, Room 750, M/C 802

Chicago, IL 60612

E-mail: tbriones@uic.edu 
